\title{
COVID-19 and Its Pathophysiology
}

\author{
Anubhuti Dixit ${ }^{1}$, Dr. Swaroopa Chakole ${ }^{2}$ \\ Type of Article: Review \\ Conflict of Interest: None \\ Funding: DMIMS \\ Ethical Approval: IEC, DMIMS, Wardha.
}

${ }^{1}$ Intern, Dept. of Community Medicine, Jawaharlal Nehru Medical College, Datta Meghe Institute of Medical Sciences (Deemed to be University), Sawangi (Meghe), Wardha-442001, Maharashtra, India,

${ }^{2}$ Professor, Dept. of Community Medicine, Jawaharlal Nehru Medical College, Datta Meghe Institute of Medical Sciences (Deemed to be University), Sawangi (Meghe), Wardha-442001, Maharashtra, India,

Emails:1anubhutid96@gmail.com, ${ }^{2}$ drswaroopachakole@gmail.com,

\begin{abstract}
BACKGROUND

COVID-19 or coronavirus disease is seriously affecting the daily lifestyle of the inhabitants of the earth. It had already created so much disturbances in terms of lives as well as livelihood.

\section{SUMMARY}

The constantly changing epidemiology and its pathophysiology of the coronavirus also known as SARS-COV-2 is creating problems in designing the containment strategy. Symptoms have changes so far since its inception in Wuhan, china. Disease management has been not all success as high virulent nature of the novel coronavirus has left the health care infrastructure overwhelmed with millions of case. The long term implications are also staring in the eyes of the researchers and needs to be solved before gaining traction.
\end{abstract}

CONCLUSION

Highly uncertain nature of novel coronavirus has been demanded greater focus on constant research. More research needs to be done in order to catalogue all the features of the virus whether changing or constant.

KEYWORDS: COVID-19, PATHOPYSIOLOGY, EPIDEMIOLOGY, DISEASE MANAGEMENT, PANDMEIC, LONG TERM IMPLICATIONS.

\section{INTRODUCTION}

COVID-19 or coronavirus disease is caused by SARS-COV-2 virus also known as novel coronavirus which belongs to the coronaviridae family. The novel coronavirus which is also the human version of the coronavirus is extremely virulent and as well as lethal in nature. (1)Every country on the globe has affected by it and people are reeling under the pressure even after one year is passed since the first cases of the disease outbreak shown in Wuhan city of the Hubei province in china. As of January 5, 2021, $86,003,887$ infection of COVID-19 has been reported across more than 200 countries and 1,860,190 are the case fatalities attributed to the complications attached to COVID-19(2). There is no slowing down for the disease and the uncertainty attached to the disease is extremely high. Unites state of America,
India, Brazil, Russian federation, France and United Kingdom are the top countries reeling under the pressure of the COVID19 pandemic(3). These country accounts for more than half of the cases of COVID19 infection and case fatalities. The case fatality rate (CFR) lies between one to two percent but overall fatalities may soon touch to two million. The epidemiology of the virus is constantly changing and updating according to the report. Varied range of symptoms and clinical outcomes are shown by coronavirus across the world. Also the recent news reports about the new mutated strain of the novel coronavirus has been a cause of concern as it is said to be more virulent than the previous one(4). UnitedKingdom and South Africa has so far reported two different strains after genomic sequencing(5). Symptoms are basic cough cold and fever like in any other influenza 
illness or flu. But the clinical outcome may vary according to the preexisting condition of the patients. Vulnerable sections are observed to produce more severe outcomes than any other groups(6). Disease management is also a challenge especially when health care infrastructure is overwhelmed with the tremendous amount of cases they are dealing. Preventive measures might be the best way in dealing with the virus and needs to be studied in detail. In this article a holistic and comprehensive over view will be taken in order to deepen the understanding about the pathophysiology of the virus.

\section{EPIDEMIOLOGY OF COVID-19}

History of coronavirus sometimes mistaken as non-existent thing as the virus wreaking havoc is named as novel coronavirus creating perception of its recent appearance. But that is not true. In fact many coronavirus strains are roaming already around the world mostly undetected. The coronavirus has a shape resembling to that of sun's outer surface that is known as corona. There are various types of coronavirus among many species of animals inhabiting the earth. Coronavirus related to human or also known as human coronaviruses were discovered in 1960's. These two viruses which belongs to coronaviridaefamily later designated to be respiratory viruses affecting the humans through lungs. It was so common that after studying the population of Italy post discovery of the coronavirus, the prevalence of the antibodies against these virus were huge and tiny percentage of people only were never infected by the virus. But as mutation is regular among viruses these no harming viruses were proven to be deadly in 2003 severe acute respiratory syndrome outbreak killing almost a tenth of the infected patients. It was caused due to SARS-COV, the earlier version of the SARS-COV-2 which is now creating ruckus all over the world. Origin of SARSCOV was supposed to be bats and transmission through some other intermediary animal which further came in contact with human. Virus jumping from one species to another in search of new home may prove extremely fatal as was seen in SARS outbreak. Then slowly itcoexist with the host without harming it. The search of other coronaviruses started and some other were also found. Pneumonia and lung disorders were initially related but later the virus expanded its scope of impact on human body. There are thousands and thousands of viruses present and many of them are present in respiratory tract. If a person gets cough or cold then the chances of the body defending against the new type of virus is high. The constant mutation creates the chain in the family changing a symptom or two every time they mutate. In 2012 another family member of coronavirus, the MERS-COV causing lethal Middle Eastern respiratory syndrome (MERS) disease. The case fatality rate was as high as 35 percent among total infection cases of 2500 patients(7).

The first cases of the novel coronavirus that is SARS-COV-2 were found in Wuhan city of the Hubei province in china. But the origin of the virus is debated till date. Various hypotheses and theories are doing the rounds among scientific and researchers fraternity as well as among common people and speculations are on all-time high. A team consisting doctors and medical professionals from various nations have been constituted by World Health Organization in order to find the origin of the virus. From previous outbreakscaused by members of coronaviridae family, the disease can be zoonotic meaning transmitted from wild species of animal to intermediate animals and then to humans. This transmission chain to humans is also called as spillover event which is supposed to be happened in wet market of Wuhan. The high virulent nature of the SARS-COV-2 can be linked to its high adaptability with the human cell receptors. The containment of the virus is a 
major challenge as virus infection cases touched to almost 86 million worldwide(8).

International committee on taxonomy of viruses has named the novel coronavirus as SARS-COV-2. It belongs to coronaviridae family of the order nidovirales. It has a size of 26 to 32 kilobases or $\mathrm{kb}$ and contains four genera of the virus in family of coronaviridae. Alpha, beta, gamma, delta are the four coronavirus genera associated. According to their appearances, these viruses are named. For example coronavirus showed spikes of proteins and resembled to the corona or crown hence named coronavirus and newest version named a novelmeans new coronavirus. It mainly starts to affect the respiratory tract but it is not confined to it and has effect on other organ systems too. There are many angiotensin converting enzyme 2 (ACE 2) receptors present in human body. These acts as a gateway to the novel coronavirus to enter into the host cell. The spike proteins attached to the virus gets bound to the ACE 2 receptors and further takes control of the host cell creating disturbances in a protein synthesis process. ACE 2 can be prominently seen on outermost cell layer of epithelial cells on various organs like trachea, lings, bronchi, respiratory tract which can be the entry point of the virus. Multiplication of the virus process then is started and they are sent to infect new cells. Virus is sensitive to wards many things such as ultraviolet light many disinfecting solvents like iso propyl alcohol. Concentrated ether with 3 quarter of concentration may also deactivate. Various vaccines to contain the spread of COVID-19 has been under development and some of them are in last stage of approval(9).

\section{SYMPTOMS AND INCUBATION PERIOD}

There are wide range of symptoms that are being reported and observed across the world. IT can broadly classified as low gradesymptoms, middle grade symptoms and severe symptoms. The symptoms actually starts from fever, cough and cold. These are milder symptoms and are the starting point of the condition to deteriorate. Other symptoms include chills, difficulty in breathing, fatigue, body aches, loss of taste and smell, sore throat, runny nose, diarrhea, nausea, vomiting and many more. Severe symptoms may include trouble in breathing, persistent pain in chest, confused state, lack of decision making ability, extreme fatigue, bluish lips or face. These although does not contain all symptoms but one should consult doctors after being in proximity of another positive patient or any other suspicious scenario. Comparing it will flu or other influenza and ignoring it can prove to be disastrous for the patient. Incubation period may vary from two days to fourteen days average being five days after the entry of the virus into the body. Virus can enter through nose, mouth, eyes, oral, fecal route but generally it enters through mouth or nose(10).

\section{DIAGNOSTICS OF COVID-19}

Diagnostics is essential in the containment strategy of the COVID-19 pandemic. The model followed includes test, trace and treat. Testing is the fundamental element and there ae many ways to do the test for COVID-19. Testing is done whether or not it is important and mere suspicion can amount to being tested for safety reasons. Generally if milder symptoms starts to show up then it is necessary to get testes. Various self-checker are given by World Health Organization to check if one got similar symptoms of COVID-19 or not. If yes then one should get tested as soon as possible so as to avoid delays which can be amounted to negligence towards health as symptoms worsens with days. Among several tests available Reversetranscript polymerase chain reaction (RT-PCR) testis considered to be the ultimate standards for diagnosing the patient. Similar test was used in SARS outbreak of 2002 to detect the SARS-COV virus, the previous version 
of SARS-COV-2. Basically the sab sample from the respiratory tract of the suspected person is taken and tested. Healthcare professional will collect the swab sample from your nose or back of throat, taking out fluid from lower respiratory tract or take saliva or stool sample as after testing samples from sewage it was found out that SARS-COV-2 can also be present in infected patients stool. The nucleic acid from the virus is then amplified and genome is detected if present. Two genes are traced and if both of them are found then the suspect is positive for the COVID-19, if only one gene is found then it is considered as inclusive. And if no gene is found then the person is considered as negative for COVID-19. A supplementary test of computedtomography can be done to take a wider look of the infection on lungs(11).

\section{CLINICAL MANIFESTATION OF COVID-19}

There are broadly two types of coronavirus disease 2019 related cases. First are asymptomatic cases and second are symptomatic cases. In asymptomatic cases the patients are usually not showing any symptoms and generally does not if they caught the infection spread by the coronavirus. Some of them are close primary contacts of confirmed positive patients, some of them got their infection during working hours. Therefore testing is necessary in order to detect asymptomatic patients. Random and widespread testing of all the people can be done to ensure there are no asymptomatic cases. Generally they are not supposed totransmit the infection as symptoms are absent which generally transmit the infection. But in some cases intimate contact with the patient may prove transmissible event. These patients need not be hospitalized if no symptoms at all are shown. They can be treated at home under clinical supervision and basic course of medicine can be provided in order to treat the patient. If some symptoms came up later in the course of treatment them immediate hospitalization must be done in order to avoid further worsening of the symptoms. The sooner you seek medical attention the better is the clinical outcome in case of coronavirus disease 2019 or COVID-19. Second instance is of symptomatic patients. These can be difficult to handle sometimes if reported later in the course of infection. Various range of symptoms include cough, cold and fever are induced in a person. Transmissibility of the disease from such person is higher than the asymptomatic patients. Therefore it is necessary to detect such persons as soon as possible so as they do not get chance to infect others in accidental way and quick diagnostics mean better chances of good clinical outcomes. Especially vulnerable groups such as comorbid patients, persons with higher age or old aged persons, pregnant women. These are already going through their immunosuppressive state. Therefore if they got the infection then it should be detected as soon as possible in order to avoid any medical complication that generally arises in such cases. In symptomatic cases, there can be subdivision on the basis severity of the symptoms. Mildlysymptomatic patients need hospitalization but in normal wards and needs only regular supervision along with proper medication. Generally they get discharged within a week or ten days as their two consecutive diagnostics tests are showing no sign of the COVID-19. But patients with comorbid conditions such as diabetesmellitus, hypertension, renal ailments and other such under lying illness, they may show severe symptoms and needed critical attention. Also late diagnosed patients are also prone to develop such symptoms. Requirement of oxygen support systems, ventilators and in turn intensive care units may arise. Their course of treatment is different and constant monitoring of the patient's condition should be done. Most of the case fatalities belongs to this group and also a cause of concern(12). 


\section{COVID-19 MANAGEMENT}

COVID-19 management is a tough task owing to the high virulent nature of the virus and its deadly nature. Almost more than one and half million people lost their lives battling COVID-19. Therefore it is important to provide best available disease management for the containment of the disease. From a study from Wuhan, china, which includes more than 44000 patients infected with COVID-19, the disease severity varies from mild to critical. Almost 4 out of five people infected with COVID-19 shows mild to moderate symptoms. Fourteen percent of them showssevere symptoms like dyspnea, or lung related malfunction and five percent of them show critical symptoms like respiratory distressleading to failure, multi organ malfunction. Over all case fatality rate lies between one to two percent of the total number of infected persons. But it goes to whooping 49 percent in persons having critical disease symptoms. As there is lack of medical professionals per unit population can be seen widely across the world and that many of the health care professionals lost their lives in COVID-19, it is important to utilize all of them judiciously so as to sustain the situation. In fact according to international nurse'scouncil, more nurses had lost their lives on CIVID-19 containmentduty than in First World War. Many countries are deprived of health care infrastructure and using it wisely will decide the course of the pandemic in that country(13).

\section{LONG TERM IMPLICATIONS OF COVID-19}

COVID-19 has not only created challenges in pretreatment and during treatment challenges. There is a grave threat of more severe long-term implications. As humanity has survived more than a year of the pandemic, the long term implications which are bound to happen, started to crop up. Various patients complaining about persistence of various medical conditions post treatment and discharge which were also seen in SARS and MERS outbreaks(14). The phenomenon is not new in coronavirus family. But dealing with this aspect is not as simple as treating the patients. From extreme fatigue to loss of taste and smell intermittently various physical symptoms that resulted into reduction in physical capacity has shown in patients of COVID-19 post illness. Also brain fog, a condition of confusion and various internalorgan conditions such as weakening of heart muscles and inflammation in alveolar tissues may worsen over the time. Proper care and rehabilitation is needed for the patients of long term illness post COVID-19 so that another disaster can be averted before shaping up(15).

\section{PREVENTIVE MEASURES}

Various compelling evidences shows us that preventive measures are way better than curative treatment in COVID-19 disease outbreak. $\mathrm{Be}$ it long term implications or lack of health care infrastructure, preventive measures can prevent you from falling into spiraling events that may found to be disadvantaged for you. From WHO to local health authorities, various measures and best practices are published and promoted by competent authorities in order to be adopted by people to safeguard themselves from the viral outbreak on their own. From wearing masks at public places to marinating safe minimum distance from surrounding human beings, these can benefit a lot in terms of viral spread mitigation $(16,17,18)$. Also appropriate personal protectiveequipment's should be provided to all the health care workers concerned to avoid them getting infected with the infection. In fact the efficacy of these measures were found in Ebola outbreak in African countries. Also along with these many edible items are good for overall wellbeing of the humans and should be consumed on daily basis in order to avoid weakening of the immune system 
which can be a cause for getting caught by the COVID-19. Vitamin C, Vitamin D, probiotics are meant to be enhancing the innate immune system response to any invasion of the external pathogens entering in the body(19-21).Oxidative stress and inflammation is increased in the body during the infection of COVID-19 which hinders in the healthy functioning of the body. These contents if taken in form of foods or supplementing safe quantity can reduce inflammation and bring antioxidant properties which in turn helps to build ones immunity. Probiotics has a lot to do with gut microbiota. And gut lung axis plays a key role in ensuring good immune system. Therefore probiotics must be included in our diet and same can act as prophylactics to ward of the viral spread of the COVID-19 (22-24). Studies on Coronavirus in special instances are reported(25-27).

\section{CONCLUSION}

The constantly changing epidemiology of the novel coronavirus is seriously creating challenges in understanding of the virus. Symptoms varied across the world and keeping it in $\log$ is necessary for further analysis. Disease management may prove difficult but home isolation of asymptomatic patients may be encouraged in order to lessen the burden on health care infrastructure which is already overwhelmed and is on the verge of collapsing. Long term implications getting some traction in last few days and needs more study to establish correlation among such trends. Post illness rehabilitative centers will be the need of the hour when more patients complaining with illness will be reported. By all looking at such scenario, the only feasible option remains is to follow preventive measures to safeguard oneself from any infection. This will not only avoid any adverse impact on the body but also relax some pressure on already ailing health sector.

\section{REFERENCES}

1. Dushyant Bawiskar, Pratik Phansopkar, Ayurva Vilas Gotmare. COVID-19 Facets: Pandemics, Curse and Humanity. Int J Res Pharm Sci. 2020 Aug 6;11(SPL1):385-90.

2. COVID-19 Map [Internet]. Johns Hopkins Coronavirus Resource Center. [cited 2021 Jan 5]. Available from:

https://coronavirus.jhu.edu/map.html

3. WHO Coronavirus Disease (COVID19) Dashboard [Internet]. [cited 2021 Jan 5]. Available from: https://covid19.who.int

4. Wise J. Covid-19: New coronavirus variant is identified in UK. BMJ [Internet]. 2020 Dec 16 [cited 2020 Dec 23];371:m4857. Available from: https://www.bmj.com/content/371/b mj.m4857

5. CDC. Coronavirus Disease 2019 (COVID-19) [Internet]. Centers for Disease Control and Prevention. 2020 [cited 2021 Jan 3]. Available from: https://www.cdc.gov/coronavirus/201 9-ncov/more/scientific-briefemerging-variant.html

6. Guan W-J, Liang W-H, Zhao Y, Liang H-R, Chen Z-S, Li Y-M, et al. Comorbidity and its impact on 1590 patients with COVID-19 in China: a nationwide analysis. Eur Respir J. 2020;55(5).

7. CDC. Coronavirus Disease 2019 (COVID-19) [Internet]. Centers for Disease Control and Prevention. 2020 [cited 2020 Nov 25]. Available from: https://www.cdc.gov/coronavirus/201 9-ncov/hcp/clinical-guidancemanagement-patients.html

8. Meng X, Deng Y, Dai Z, Meng Z. COVID-19 and anosmia: A review based on up-to-date knowledge. Am J Otolaryngol [Internet]. 2020 [cited 2020 Nov 24];41(5):102581. Available from: https://www.ncbi.nlm.nih.gov/pmc/ar ticles/PMC7265845/ 
9. Yuki K, Fujiogi M, Koutsogiannaki S. COVID-19 pathophysiology: A review. Clin Immunol Orlando Fla [Internet]. 2020 Jun [cited 2020 Nov 24];215:108427. Available from: https://www.ncbi.nlm.nih.gov/pmc/ar ticles/PMC7169933/

10. Azer SA. COVID-19: pathophysiology, diagnosis, complications and investigational therapeutics. New Microbes New Infect [Internet]. 2020 Sep 1 [cited 2020 Nov 24];37:100738. Available from:

http://www.sciencedirect.com/science /article/pii/S2052297520300901

11. Liu X, Liu C, Liu G, Luo W, Xia N. COVID-19: Progress in diagnostics, therapy and vaccination. Theranostics [Internet]. 2020 Jun 19 [cited 2020 Nov 24];10(17):7821-35. Available from:

https://www.ncbi.nlm.nih.gov/pmc/ar ticles/PMC7359073/

12. Mason RJ. Pathogenesis of COVID19 from a cell biology perspective. Eur Respir J [Internet]. 2020 Apr 1 [cited 2020 Nov 24];55(4). Available from:

https://erj.ersjournals.com/content/55/ 4/2000607

13. Tahamtan A, Ardebili A. Real-time RT-PCR in COVID-19 detection: issues affecting the results. Expert Rev Mol Diagn [Internet]. 2020 Apr 22 [cited 2020 Nov 24];1-2. Available from: https://www.ncbi.nlm.nih.gov/pmc/ar ticles/PMC7189409/

14. Batawi S, Tarazan N, Al-Raddadi R, Al Qasim E, Sindi A, AL Johni S, et al. Quality of life reported by survivors after hospitalization for Middle East respiratory syndrome (MERS). Health Qual Life Outcomes [Internet]. 2019 Jun 11 [cited 2020 Dec 18];17(1):101. Available from: https://doi.org/10.1186/s12955-0191165-2
15. Palmer K, Monaco A, Kivipelto M, Onder G, Maggi S, Michel J-P, et al. The potential long-term impact of the COVID-19 outbreak on patients with non-communicable diseases in Europe: consequences for healthy ageing. Aging Clin Exp Res. 2020 Jul;32(7):1189-94.

16. Güner R, Hasanoğlu I, Aktaş F. COVID-19: Prevention and control measures in community. Turk $\mathrm{J}$ Med Sci. 2020 Apr 21;50(SI-1):571-7.

17. Feyaerts AF, Luyten W. Vitamin $\mathrm{C}$ as prophylaxis and adjunctive medical treatment for COVID-19? Nutr Burbank Los Angel Cty Calif [Internet]. 2020 [cited 2020 Dec 10];79:110948. Available from: https://www.ncbi.nlm.nih.gov/pmc/ar ticles/PMC7381407/

18. Parveen, S., and S. Jain. "Pathophysiologic Enigma of COVID19 Pandemic with Clinical Correlates." International Journal of Current Research and Review 12, no. 13 (2020): 33-37. https://doi.org/10.31782/IJCRR.2020.1 2136.

19. Chakole, S., and V. Jaiswal. "A Review Paper on Pandemic COVID19." International Journal of Research in Pharmaceutical Sciences 11, no. Special Issue 1 (2020): 994-99. https://doi.org/10.26452/ijrps.v11iSPL 1.3404 .

20. Chandankhede, K.J., and R.K. Chandankhede. "Pandemic Disease and Infectious Disease in Ayurveda with Special Reference to Covid-19." International Journal of Research in Pharmaceutical Sciences 11, no. Special Issue 1 (2020): 292-96. https://doi.org/10.26452/ijrps.v11iSPL 1.2715 .

21. Chaple, J.N. "Ayurveda and Vyadhikshamatwa (Immunity) during COVID 19." International Journal of Research in Pharmaceutical Sciences 11, no. Special Issue 1 (2020): 135155 . 
https://doi.org/10.26452/ijrps.v11iSPL 1.3639 .

22. Chaudhari, B.V., and P.P. Chawle. "Life Lessons of the Pandemic "COVID-19"." International Journal of Research in Pharmaceutical Sciences 11, no. Special Issue 1 (2020): 469-71. https://doi.org/10.26452/ijrps.v11iSPL 1.2814 .

23. Juneja, S., S. Dangore-Khasbage, and R.R. Bhowate. "Role of Vitamin $d$ in Prevention of Corona Virus Infection (Covid-19)." International Journal of Research in Pharmaceutical Sciences 11, no. Special Issue 1 (2020): 407-10. https://doi.org/10.26452/ijrps.v11iSPL 1.2737 .

24. Khan, S., S. Quazi, and M. Kaple. "The Demographical and Epidemiological Profile of Coronavirus Disease 2019 (Covid-19)A Review." Journal of Critical Reviews 7, no. 10 (2020): 4-8. https://doi.org/10.31838/jcr.07.10.02.

25. Kothari, L., S. Wadatkar, R. Taori, P. Bajaj, and D. Agrawal. "Coronavirus:
Towards Controlling of the PandemicIndian Scenario." International Journal of Research in Pharmaceutical Sciences 11, no. Special Issue 1 (2020): 462-68. https://doi.org/10.26452/ijrps.v11iSPL 1.2813 .

26. Lohiya, S.B., S. Damke, and R. Chaudhary. "Coronavirus Disease (COVID) 2019 in Children - A Short Review." International Journal of Current Research and Review 12, no. 17 (2020): 172-77. https://doi.org/10.31782/IJCRR.2020.1 21726.

27. Sonone, A., A. Hande, M. Gawande, and S. Patil. "Sickle Cell Individuals Are Less Vulnerable for Corona Virus Disease 2019-an Enigma." International Journal of Research in Pharmaceutical Sciences 11, no. Special Issue 1 (2020): 1015-17. https://doi.org/10.26452/ijrps.v11iSPL 1.3427 . 